\title{
Updating the Argument for Permitting and Federally Funding Stem Cell Research
}

\author{
Michael Roess ${ }^{1} \cdot$ Andrew Flescher ${ }^{2}$
}

Published online: 12 September 2015

(C) Springer International Publishing AG 2015

\begin{abstract}
Stem cell technology has advanced in recent years, raising the question of whether we might be able to bypass those concerns which traditionally have troubled opponents of stem cell research the most. In this light, we examine the major new techniques for the creation of human stem cell lines (HSCs), including induced pluripotent stem cells (iPS) and somatic cell nuclear transfer (SCNT) in order to assess whether either of these two alternatives are practically or ethically more advantageous than a reliance on the use of embryos procured in excess from in vitro fertilization (IVF). We conclude that these more recent techniques provide neither functionally comparable alternatives nor a straightforward escape from the moral difficulties involved in embryonic destruction. We then address anew the question of permissibility of stem cell research in comparison with two other biomedical ethical issues, namely, abortion and euthanasia. Finally, availing ourselves of the doctrine of double effect, we advocate for a permissive policy regarding the use of embryos in stem cell research and additionally provide fresh grounds for allocating federal funds for this research within a pluralistic society.
\end{abstract}

This article is part of the Topical Collection on Ethics in Stem/Progenitor Cell Therapeutics

Andrew Flescher

Andrew.Flescher@stonybrookmedicine.edu

1 Center for Medical Humanities, Compassionate Care and Bioethics, Stony Brook University, Health Sciences Tower, Level 3 Room 080, Stony Brook, NY 11794-8335, USA

2 Core Faculty, Program in Public Health, Associate Professor of Preventive Medicine, Associate Professor of English, Stony Brook University, Health Sciences Tower, Level 3 Room 071, Stony Brook, NY 11794-8338, USA
Keywords Stem cell ethics · Pluripotency $\cdot$ Double effect . Induced pluripotency $\cdot$ Human embryonic stem cells $\cdot$ Somatic cell nuclear transfer

\section{Introduction}

The 2016 presidential election provides the USA with another opportunity to reevaluate its stem cell research policy. As stem cell technology has advanced significantly since the current policy was established, we examine new techniques for the creation of stem cell lines, including induced pluripotent stem cells (iPS) and somatic cell nuclear transfer (SCNT). While longtime opponents of embryo-destroying stem cell research insist that iPS techniques provide an ethically acceptable alternative [1], it is not clear that iPS techniques produce functionally comparable stem cell lines $[2 \cdot \bullet]$ or involve fewer moral difficulties than embryo-destroying alternatives [3-5]. After examining these three techniques, we will raise again the question of permissible embryo destruction for research purposes, comparing this practice to the similar biomedical issues of abortion and euthanasia. Using the doctrine of double effect, we conclude that the current permissive policy regarding embryonic destruction is appropriate. Furthermore, we suggest that resources exist for a potential consensus between religiously motivated objectors to federal funding for embryonic destruction in stem cell research and its advocates in the narrow case of excess in vitro fertilization (IVF) embryos that would otherwise be destroyed or preserved indefinitely.

\section{Current State of Regulation}

Any discussion of the ethics of stem cell research ought to be guided by a clear understanding of the current policy. In the 
USA, all forms of stem cell research may be and are legally practiced. Federal restrictions involve only the use of public funds for such research. Since 1995, federal funds have been unavailable for any research that involves the destruction of human embryos or their creation for research purposes. While this prohibition, codified in the "Dickey Amendment" that originated in Congress as a rider attached annually to the appropriations bill funding the Department of Health and Human Services (DHHS), has continually been in effect since the Clinton administration, stem cell policy in the USA has undergone significant changes over this time. As the executive branch is in charge of the DHHS, the president has enormous discretionary power over how its funds are used. In 2001, then President Bush prohibited the use of federal funds for research not only involving the destruction of embryos for the sake of creating new human embryonic stem cell (hESC) lines, but also using of any hESC lines created after August 9, 2001. Since hESC lines degrade in quality over time, this effectively eliminated any long-term prospects for federally funded stem cell research. As methods for creating stem cell lines that did not involve the destruction of human embryos were developed, the Bush administration revised this policy to permit federal funding for research on hESC lines, the creation of which did not involve the destruction of any human embryos.

Shortly after entering office, President Obama lifted any executive branch restrictions on stem cell research, while continuing to sign congressional funding bills for DHHS that included the Dickey Amendment. While this change in policy would not take full effect until litigation was resolved in 2011, it has had the effect of permitting federal funding for research involving new hESC lines that were themselves created privately while prohibiting funding for the creation of new stem cell lines through most available techniques.

It is worth reexamining the ethics of stem cell research presently both because new techniques for the creation of hESCs have been developed since the current policy was put into place and because any presidential election can occasion the reevaluation of presidential and, far less likely, congressional guidelines for federal stem cell policy.

\section{The Current State of the Science}

The sought after property of human embryonic stem cells (hESCs) is their pluripotency, a quality that has come under definitional scrutiny in recent years [6]. In the loosest sense, it refers to the ability of any cell to replicate itself indefinitely and also to differentiate into cells along all three germ lines [6, 7•]. More strictly, it describes only those cells that can reconstitute an entire organism $[6,7 \bullet]$. Pluripotent cells occur naturally only in embryos during the blastocyst phase of development, about 5-11 days after fertilization, when the embryo is constituted by at most a few hundred cells. Since the turn of the century, two successful alternative techniques for the creation of pluripotent stem cells have been developed. Presently, there are three available methods for obtaining pluripotent stem cells: the traditional process of destroying blastocysts created in vitro, inducing pluripotency by reprogramming adult cells (iPS), and creating stem cells through a process of somatic cell nuclear transfer (SCNT) [7•]. In this section, we will briefly discuss the differences between these methods, paying close attention to the ethical concerns raised by iPSs, which are often hailed as the answer to the ethical problems facing stem cell research.

\section{IVF Produced hESCs}

Pluripotent hESCs are produced naturally by the human body, but only during the blastocyst phase of development. Because of the narrow time frame involved, hESCs can only be obtained from an embryo fertilized in vitro. While they are still created in an artificial environment, these are the only known naturally occurring pluripotent HSCs [7•]. Until 2007, the only way to obtain hESCs was the destruction of embryos created in vitro either for research or for reproductive purposes. It is worth noting that the USA currently houses upward of 400,000 frozen embryos at IVF facilities, with many held in excess [8]. Because of the difficulties involved in IVF fertility treatments - and because of our noteworthy permissive attitude toward facilitating parenthood in this countrymost couples who pursue pregnancy this way will fertilize more eggs than they plan to use. Any excess eggs can be stored indefinitely (at a cost), discarded, donated to another couple seeking a child, or donated to research, including stem cell research. Thus, there are means of obtaining hESCs that involve embryonic destruction but that do not also involve the creation of embryos for research purposes.

Because they are naturally occurring and not subject to any genetic manipulation, hESCs are the touchstone against which we must measure alternative techniques for creating pluripotent stem cells. As hESCs are created by fertilization processes, they cannot be used to create stem cells with an identical genetic profile to a currently living adult, limiting their usefulness for "personalized medicine." Currently, the creation of hESC lines cannot be funded by federal research dollars, but federally funded research involving hESC lines created privately is permitted.

\section{Induced Pluripotent Stem Cells (iPSs)}

Pluripotency has been induced in fully differentiated adult cells through a process of genetic "reprogramming." The technique was first developed in Japan where induced pluripotency was attained in the cells of mice in $2006[9 \bullet$, 10]. In the following year, several labs independently applied 
this technique to humans, successfully creating the first human iPSs [9॰]. The techniques involved in creating iPSs require significant genetic manipulation, although they have been continually refined since first developed in 2007 [11•]. iPSs have often been hailed as a solution for the ethical qualms facing stem cell research because (1) they do not require the creation of a human embryo and, thus, research involving iPSs does not require embryonic destruction, and (2) they can be derived from an adult patient and will consequently have nearly the same genetic makeup as the adult patient, although differences resulting from the process of inducing pluripotency have been observed [12]. Currently, federal funding may be used for both the creation and use of iPS lines for research purposes.

\section{SCNT or "Therapeutic Cloning"}

A theoretical goal for years, SCNT was not successfully employed on human cells until 2013. SCNT involves replacing the nucleus of an oocyte with one obtained from the cells of an adult human and inducing cellular division, at which point the egg begins the normal process of maturation. When it reaches the blastocyst phase, it is destroyed in order to obtain the hESCs just as would be done for IVF-produced hESCs. From the therapeutic and research perspective, SCNT is perhaps the most promising of the three techniques. It has the advantage of creating stem cells that are genetically identical to the donor. While this is also true of iPSs, SCNT involves far less genetic manipulation to accomplish and, thus, more closely approximates naturally occurring hESCs.

From an ethical and legal perspective, however, SCNT is, at best, no better than the traditional method of obtaining hESCs as both involve the destruction of a human embryo. In fact, SCNT raises additional ethical and legal questions because it involves an embryo that (1) is created specifically for research purposes and (2) is created using the same techniques that would be employed by reproductive human cloning. Currently, federal funding is unavailable for the creation of HSCs by SCNT, although it can be used on cell lines created privately through this technique. While private and New York State-funded research employing SCNT is currently ongoing in the USA, it is also among the most controversial. Leon Kass, the most prominent opponent of the practice, has strongly advocated publicly for an outright ban on SCNT research over and above the prohibition of federal funding on the grounds that the techniques involved in human cloning are corrosive to human dignity, and several bills have been introduced in the senate to this effect, although none have passed to date [1].

Advocates for SCNT often dismiss its detractors as luddites, insisting that the technology is to be pursued principally because it is currently the most promising on the scientific horizon. They insist that we are to avail ourselves of what technology has proximately in store for us as part of our pursuit of the human good. By this view, technology that is a possibility should, ipso facto, be made a reality [13]. This argument is based on a kind of bioethical "manifest destiny" according to which "we should do it because we can do it." More cautious in our assessment of new technologies, we recommend that each ought to be considered in its context, asking always what are its costs and its benefits, particularly when alternatives are available. We recognize that there can be legitimate moral objections to the embrace of new technologies, however promising they may be. As we have not, as a nation, settled the question of whether the destruction of human embryos that were created for acceptable purposes ought to be permissible, we think it best to focus our attention on this question, as it is a primary consideration in hESC research and is a necessary but not sufficient condition for any ethical evaluation of SCNT research. Thus, we are skeptical that SCNT represents a viable moral alternative to $\mathrm{hESC}$ at this time in terms of helping us to bypass the same objections critics have traditionally had with stem cell research.

\section{Do iPSs Resolve the Moral Issues of Stem Cell Research?}

The most urgent question before us at the moment that new technological developments pose is whether iPS technology provides an adequate replacement of embryo-destroying techniques for obtaining new stem cell lines, as some have claimed [1]. Prior to the development of techniques for the creation of iPS lines, objectors to research involving the destruction of human embryos insisted that alternative means for obtaining pluripotent stem cells would be developed [12]. Many who had argued against the use of hESCs in research in the 1990s and 2000s claimed vindication when iPS technology proved successful not only for creating pluripotent stem cell lines but also for creating cell lines containing a specific individual's DNA, a goal for stem cell research that is impossible to obtain using excess IVF embryos to derive new HSC lines [1, 12]. However, in the years since the development of successful iPS techniques, these claims have confronted both moral and practical objections.

On a practical level, differences between hESCs and iPSs have been discovered. Early research was long troubled by the possibility that the genetic manipulation involved in iPS techniques would introduce significant differences between iPSs and hESCs. Initial studies showed that iPSs appear to have a persistent "epigenetic memory" and are at best more successful at producing differentiated cells along the same germ line from which they were derived $[7 \bullet, 9 \bullet]$. While techniques to induce pluripotency continue to be better understood and refined $[2 \bullet \bullet, 11 \bullet]$, a recent study of the differences between iPSs and hESCs indicated a myriad of differences, 
notably "super-enhancers transcriptionally active specifically in ESC and associated with genes implicated in the maintenance of pluripotency" [2••]. While iPSs and hESCs may prove to be therapeutically comparable in spite of these differences, it looks increasingly less likely that this will be the case with current techniques. At best, it is too early to make such a claim with any conviction; we simply do not know what impact the differences between hESCs and iPSs will have on the therapeutic potential of stem cells. Limiting our research to only iPS-derived lines would prevent or seriously inhibit our ability to evaluate these differences [9॰]. It is too early to declare iPSs a comparable alternative to hESC research that some advocates have claimed it to be $[2 \cdot \bullet, 7 \bullet]$.

Furthermore, over and above these practical objections, several moral objections have been raised against the use of iPSs as an ethically superior alternative to hESCs. The first of these involves the ontological status of iPSs. When the President's Council on Bioethics endorsed the potential of techniques for inducing pluripotency, they did so with the caveat that the boundary between pluripotency and totipotency not be crossed [12]. This barrier was erected by opponents of traditional hESC research to ensure that cells containing the potential to develop into a full human life not be destroyed for research purposes. However, the meaningfulness of this threshold has been called into question. Insofar as the same process that creates iPSs could be used to generate totipotent cells that could, in turn, create human life, it has been argued that iPSs should be understood as existing on a "continuum with the processes of natural fertilization and SCNT" [3, 4]. If the technique required for inducing pluripotency could also induce totipotency, then the distinction between the potential for human life found in blastocysts created through SCNT or IVF and that found in iPS may be a matter of degree rather than kind [3]. Additionally, it has been argued that iPS research is ethically complicit with the destruction of human embryos both because the techniques employed in its development would not have been possible without such destruction and because its present research agenda presupposes the creation of additional embryonic cell lines [5].

With open questions about the ethical differences between iPSs and hESCs and their therapeutic comparability, it is clear that we cannot simply appeal to the existence of iPS technology as a means of avoiding the difficult moral question over whether it is appropriate to engage in research that requires the destruction of human embryos when the suffering of those who may be aided by such research lies in the balance. The past decade has seen progress in both the basic science of stem cell research, with improved techniques for inducing pluripotency and the successful use of SCNT on human cells, and in attempts to redeem the therapeutic promise of stem cell research, including the demonstrated improvements in sight among those suffering from age-related macular degeneration $[11 \bullet, 14 \bullet]$. In spite of these technological advances, however, we have seen no real progress on ethical or policy matters since they were first raised in the 1990s at a time when the potential benefits of HSC therapies were far more speculative. Induced pluripotency has not yet become the ethical panacea many had hoped, and the Dickey Amendment remains the law of the land. In the remainder of this paper, we therefore return to the question of permissibility and attempt to provide grounds for federally funding stem cell research in our contemporary climate.

\section{On the Permissibility of Stem Cell Research}

Are there features of stem cell research that make this issue distinctive from others in bioethics that involve the destruction of human life, potential or otherwise? Leon Kass and others oppose research on non-induced (i.e., embryonic) pluripotent stem cells because they hold that human embryos, which must be destroyed in the process of isolating and using these cells, are themselves human life, have intrinsic value, and therefore should not be deployed for any instrumental end. Objections pertaining to the "sanctified status" of the blastocyst, based on the premise that human life is not ours to destroy, are essentially the same as those raised against euthanasia and abortion [15]. While for the sake of argument we may grant that such an objection has merit, unless we determine that this objection is an overriding one, the fact that it is essentially the same sort of objection in each of these three cases does not mean that we ought to reach similar conclusions about permissibility of all three practices. In each instance, we must look carefully at cost-benefit calculations and consider what is of most value in human life. A comparison between the three issues may give us guidance regarding stem cell policy. This process will play out differently depending on the issue, as well as on how the issue is framed.

In considering the ethics of euthanasia, the good entailed in stopping the pain of the individual suffering from an end stage disease is weighed against what ending an individual's life early might imply about the value of that life. In the case of abortion, the argument over permissibility is frequently construed as a contest between a mother's well-being, including control over her body, and the rights of an unborn baby. In these instances, the costs and benefits of adopting an attitude of permissibility vary in important ways. However, in neither instance does the health and well-being of an individual currently alive stand to improve dramatically over the course of a lifetime, as they do in the case of stem cell research.

The benefits of stem cell research bear not on life yet to be born, or on the timing and circumstances of one's death, but on the possibility of altering the life-threatening, often painful circumstances under which one labors throughout the majority of one's life. For this reason, we should think about the permissibility of conducting stem cell research differently from 
other issues in biomedical ethics with which it is sometimes compared. This is not to say that convincing arguments cannot be made on behalf of the permissibility of euthanasia or abortion, but rather that the weight of the potential good provides the strongest prima facie argument for permissibility among these issues in the case of stem cell research. In making this case, one caveat bears rementioning. At this point in time, we have not yet perfected the stem cell technologies which could be used for life-saving therapies on behalf of those suffering from degenerative diseases or injuries. We have promising leads, but we cannot, at present, use pluripotent stem cells to treat illnesses ranging from age-related macular degeneration to repairing spinal cord injuries that leave patients permanently paralyzed. Thus, as we go on to consider the prospective benefits of such therapies, we will assume, with the majority of scientists who have looked carefully at the prospects for perfecting stem cell technology, a great likelihood of the eventual, if not imminent, successful development of these stem cell therapies $[14 \bullet, 16,17]$.

\section{Benefits}

Stem cell research bears directly and urgently on the wellbeing of individuals presently alive - individuals in desperate need of being cured of a serious affliction from which they are suffering. As mentioned above, what lays at stake in stem cell research is not the protection of potential human life (as in the case of abortion), or the manner in which we end human life (as in the case of euthanasia), but the saving or significantly improving the health and, in turn, the flourishing quality of life of living human beings $[18,19]$. We say this careful not to patronize the disabled or those suffering from serious maladies, as if to suggest that their lives do not already have robust quality, or that we are somehow experts on what in the first place constitutes "quality of life." On the contrary, in this judgment, we are trusting not philosophers, but patients who suffer from diseases from which stem cell therapies represent a potentially viable remedy. When polled, such individuals, as well as their family and friends, are resoundingly in favor of stem cell research [20, 21]. Furthermore, we are talking about a sizable population of individuals. As cell biologists Philip H. Schwartz and Peter J. Bryant write,

It has been estimated that over 100 million patients in the United States might benefit from stem-cell based therapies. The most numerous of these patients are those affected by cardiovascular disease (79.4 million, American Heart Association 2007), autoimmune diseases (14.7 to 23.5 million, National Institute of Allergy and Infectious Diseases 2005), type 1 and type 2 diabetes (20. 8 million, American Diabetes Association 2007), osteoporosis (10 million, National Institute of Arthritis and Musculoskeletal and Skin Diseases 2007), cancer (10.5 million, National Cancer Institute 2006), Alzheimer's Disease (4.5 million, Alzheimer's Association 2005), and Parkinson's disease (1.5 million, American Parkinson's Disease Association 2003) [22].

Schwartz and Bryant also allude to stem cell therapies currently within our grasp, where, using bone marrow, umbilical cord blood, or peripheral blood stem cells, clinicians have already been able to treat many disorders of the blood and immune systems [22]. While the estimate of over 100 million beneficiaries of stem cell research is admittedly not 100 million people living in the immediate present, we are not so many years away from the research bearing its promised fruits so as to render fatuous claims that "we are close." Stem cell researchers are, for instance, closer to delivering on their promise to future victims than biomedical engineers of vital organs are to furnishing a solution for our organ shortage problem. In context, 100 million is still a big number. In comparison to physician-assisted suicide, which commands a lot of attention in bioethics these days, stem cell research is poised to affect a vastly greater number of people than the number of suffering individuals who would choose to avail themselves of physician-assisted suicide if they had the option. (For example, despite the legality of physician-assisted suicide (PAS) in Oregon since the state's Death With Dignity Act went into effect in 1997, just over 750 people have availed themselves of this right. And, PAS is only legal in two additional states.) In terms of quantitative magnitude, it seems, there is hardly a biomedical technology that stands to impact human lives more significantly than this one.

In light of the fact that embryos created but no longer intended for reproductive purposes through IVF already exist in excess, the benefit of using them begins to loom larger than the cost of doing so. Some of the maladies stem cell research would address include birth defects, Parkinson's disease, cancer, amyotrophic lateral sclerosis (ALS), and Alzheimer's disease. Those who suffer from these conditions are functionally impeded in nearly every aspect of their lives. Such individuals do not merely suffer from the disease that afflicts them, but the ill-ness (literally, the chronic state of being ill) that characterizes their existential predicament. For such individuals, what lies in the balance is no less than the continuing, loving, and flourishing relations they have made with others. These are not relationships that exist prospectively, as they do in the case of fetuses. Stem cell research, in being utilized for the sake of eradicating the diseases named above as well as many others, has the prospect of extending and bettering the actual lives, and in turn the relationships formed in those lives, of suffering patients.

Contrast these stakes to those in the case of euthanasia, where ethical discussions focus narrowly on the manner in which one dies. Euthanasia humanely calls attention to the 
process of death in the life cycle. However, it does not in any fundamental way provide a cure for death or pain at the end of life. No doubt, the virtues of mercy and compassion lie at the heart of the proponent's call to action. This said, advocating for one's right to procure a "good death" on one's own terms pertains only to the final phase of one's life, not to one's life in its entirety. Death is a natural part of the life cycle and cannot be stopped for those suffering from end-stage diseases, even if it occasionally can be hastened in cases where deemed appropriate to prevent undue suffering. By contrast, the successful development of stem cell therapies has the potential to slow, if not altogether remove, the burden those afflicted with lethal and life-stultifying disease or injury must face when choosing between the lesser evils of death and suffering until death. Here, in contrast both to Kass and to thoroughgoing advocates for euthanasia, we acknowledge a conviction about what we believe renders meaningful the often articulated claim that human life is "sacred." What gives life its value is not merely the biological fact of life itself, or the pleasure (or lack of pain) experienced in life, but the relationships one forms between oneself and one's world, between oneself and others, and between oneself and all other beings that a life underway affords.

How does the issue of stem cell research compare with that of abortion in terms of assessing the benefits? Again, this time perhaps controversially, we suggest that there is more to gain by adopting a permissive attitude toward stem cell research than by backing either the pro-choice or a pro-life position precisely because we are talking about an actual life underway rather than a life yet to be born. Those who defend the inalienable right for one to make decisions over one's body might demur. Susan Jarvis Thomson, for example, offers the famous analogy between a renowned violinist, hooked up to an individual against his will for over 9 months for the greater good of preserving this violinist for the whole world's benefit, and the pregnant woman who is forced to deliver a baby, to appeal to our sensibility that no one has the right to subvert the prerogative of an individual to make choices about how one will spend one's waking moments [23]. Just as we would not strip anyone of his or her freedom for the sake of the violinist, we should not force a potential mother to use her body to carry a fetus to term. Thomson appeals to justice in arguing that freedom over oneself is a right to be prized over all others [23]. For the sake of argument, she grants "life at conception" and then proceeds to argue that the killing of prenatal life is nevertheless justified if the cost of bringing such life to term is the imprisonment of the women it would entail. While we do not weigh in here on her dispute with those who regard such killing as murder, we do wish to point out that it behooves the defender of Thomson, who sees the impregnated individual much like the individual captured for the sake of keeping the world-renowned violinist alive, also to recognize the potentially avoidable imprisonments of those afflicted with injuries or diseases that stem cell therapies might erase. In this case, however, sufferers are imprisoned to endure their predicaments over a lifetime, not just for $9+$ months.

In kind, we suggest that the lives of unborn babies in their first two trimesters, beings that as of yet have no sentience, self-awareness, or formed relationships with other human beings, represent constituents of our protection, whatever their moral status, the defense of whom should be placed in their proper context. Those suffering from major injuries or diseases possibly treatable by stem cell therapies have full sentience and self-awareness and have already formed meaningful relationships with others. There are, consequently, ample grounds for understanding the defense of their interests to be embraced by rather than seen as an impediment to a "culture of life," even more than the defense of the interests of fetuses are so seen to be by the pro-life movement.

To summarize, in terms of its prospective benefits, stem cell research would seem to be the technology with the greatest potential to improve the welfare and well-being of individuals whose full lives are ahead of them. If perfected, it impacts not future or possible lives, or a small phase of a person's life, but actual ongoing lives of humans presently suffering.

\section{Costs}

Like the issues of euthanasia and abortion, stem cell research has its costs. For starters, in all three cases, the normal process by which life and death naturally transpire is arguably disrupted. Subscribers to a "sanctity of life" doctrine, according to which human beings should never "play God," are likely to raise objections about any practice in which human life is either destroyed prematurely (euthanasia) or preempted from coming to term in birth (abortion and hESC research). The case of stem cell research is most like abortion in that it entails the destruction of an embryo, though one that was created in a lab and has not yet been implanted into a womb. Thus, for those who believe that human beings begin to exist with the presence of one-cell zygote at fertilization [24], or even those who believe that potential human life ought to be treated the same as actual human life [25, 26], neither abortion nor stem cell research ought ever to be allowed, as human beings are prohibited from being used as an instrumental means in pursuance of the good of other human beings. Things become even more problematic in the case of stem cells if we include instances in which embryos are created specifically for the purpose of research, where their destruction is not just foreseen, but intended (as in SCNT).

The variations on debates over whether blastocysts are to be accorded the protections given to all life are almost as extensive and difficult to resolve definitively as are corresponding discussions over the question of when life begins. The majority of these debates are well rehearsed in the 
literature; due to constraints of space, we will not be able to do them all explanatory justice here [26, 27]. Relevant issues include, but are not limited to, the following: whether embryos have intrinsic value from conception, regardless of when "life" technically begins; what the merits of "potential personhood" are relative to actual personhood; whether, independent of moral status, allowing the destruction of embryos sets a dangerous precedent (slippery slope) for other body parts to be commodified in service of a greater good; what constitutes moral status in the first place; and what perils we stand to face if we engage in the kinds of "quality of life" assessments of determining moral status (e.g., Are we arbitrarily elevating "sentience" or "self-awareness" above other relevant indicators?). Each of these issues raises debates that welcome intelligent defenders of positions on both sides, and their collective consideration has even given rise to some interesting hypothetical philosophical discussions about what constitutes a unique human identity (or rather, under what circumstances, the uniqueness of human identity can be established) [28].

We will not resolve these debates here, but it does seem to be the case that in terms of the question of costs, in contrast to that of benefits, we ought to come to similar, if not the same, conclusions about stem cell research as we do in the case of other critical biomedical ethical issues, certainly as we do for abortion. This is to say that if we determine that a zygote has the same moral status as a living human being, then its intentional destruction cannot be justified regardless of what great good lays at stake. Here, we may invoke recent work by biologists and cognitive scientists that has been done on moral intuitions in the context of "trolley problems," which affirm a Kantian maxim of "respect for persons": There are neither rational nor intuitive grounds to see ourselves as justified in intentionally killing (i.e., murdering) one to save many [29, 30]. This said, the empirical determination on which such a scenario reliesthat stem cells do in fact have the same moral status as living human beings - can only be answered decisively in the affirmative provided one takes a prior leap of faith, for we are not yet in any position to conclude scientifically that embryos are full-fledged human life. As we cannot conclude that embryos ought to be granted the same moral status as living human beings scientifically, we might stipulate that we ought to avoid embryo destruction, ceteris paribus - even if they are not fullfledged human life, they are the building blocks of life and retain some certain value-without considering the protection of embryos to be a trump card that precludes all research. In absence of scientific, and thereby normative, consensus on the moral status question, we must consider the relative pragmatic benefits of engaging in such research versus the benefits of not doing so. At present, we do not have enough knowledge to make the question of costs the key issue through which to examine the ethics of stem cell research.

No doubt, even if one remains agnostic about the question of moral status, there are reasons to regard the destruction of embryos as entailing significant costs. Permitting research on stem cells means the ending of potential life, which is not to be taken lightly, and it additionally means overriding the deeply held values of a significant constituent of our citizenry. Stem cell research, regardless of one's background or convictions, is not cost-neutral. Thus, we recognize that there will always be a burden for the proponent to demonstrate that the cost is worth it.

\section{Double Effect}

In light of the forgoing ethical analysis, we believe that this burden can be met. In this spirit, we now wish to introduce a constructive argument on behalf of the permissibility of embryo-destroying stem cell research (and, by extension, funding such research). The argument we propose avails itself of a principle of "double effect." According to this principle, one is permitted to act in pursuance of an overall good that entails a harm - in this case, the harm of destroying embryos - if two conditions are satisfied: (1) The acting agent pursues the good such that any bad effect that occurs as a result is at most foreseen but never intended and (2) that bad effect never outweighs the overall good in whose larger service it came to be (which also assumes that the acting agent will go out of one's way to minimize harm). Specifically, we wish to defend the position that we are morally justified in permitting embryonic destruction in stem research in the case of embryos that have already been created for reproductive reasons and that will be discarded (or preserved indefinitely) anyway. In these cases, the destruction of an embryo is not directly sought as the means of research but is rather a by-product of that research. As such, no harm is ever intended by stem cell research. Furthermore, since there are many more embryos created for reproductive purposes than are needed or can be used for those purposes, more good than harm is ultimately done in permitting their use for such a worthy cause as the potential curing of severe injury and disease. (We do not weigh here in on the case of embryos that are created for the designated purpose of being destroyed, as happens with SCNT. This is, obviously, a harder case to make.)

In defending this view, we might pause to ask why we have an excess of embryos in the first place. For better or for worse, in our moral examination of the reproductive rights of individuals, we have decided as a society that the good of providing aid and assistance to parents having difficulty conceiving justifies the foreseeable but not intended destruction (or indefinite ignoring) of extra embryos, the by-product of our process of facilitating conception. In other words, we have already decided as a society that double effect is a legitimate basis on which to justify the creation of extra embryos in the case of helping prospective parents conceive. To maximize 
reproductive success, IVF requires that we fertilize more, indeed many more, eggs than are implanted in any given attempt.

Note that the cost of dealing with excess embryos borne by the IVF process is exactly the same as in the case of stem cell research: The decision to discard extra embryos, in both cases, is what directly leads to their destruction. Any decision to use embryos for research merely alters the manner of destruction, which has already been predetermined [31]. While the costs to extra embryos in these two cases are the same, the benefits are arguably greater in stem cell research than they are in IVF. Indeed, the ambition of curing terrible injury and disease is manifestly more impacting than that of giving individuals having a difficult time conceiving more reproductive options. Here our convictions are consistent: As we did above, we assign the most morally urgent priority to attending to the needs of human beings who are currently suffering. We therefore admittedly place a higher value on alleviating the considerable pain and severe life restrictions experienced by individuals who could benefit from stem cell therapies than we do on relieving the psychological anguish experienced by those unable to raise their own genetic progeny (which is not to say that this is not a worthy ambition as well).

If we determine that the creation of new living human beings is something that figures into the overall good (as we have, in fact, so determined as a society in adopting such a permissive attitude with regard to IVF), it stands to reason that the preservation of the welfare and well-being of those currently alive ought to figure into the pursuance of the overall good all the more, thereby making the grounds for double effect even stronger in the case of stem cell research than in the case of IVF. In any case, in our analysis, we have at most piggybacked off of the same argument from double effect (foreseeable but unintended embryonic destruction) already in play with IVF, having operated, if anything, according to an additional principle of conservation where we make the best moral use of extra embryos, thereby abiding the constraint of "mitigating harm."

At this point, one might raise an objection questioning whether it is really the case that the stem cell researcher has not dirtied his hands in choosing to conduct research on already existing stem cell lines [5]. Is this really an instance of foreseeable but not intended harm? Indeed, if it becomes widely known that it is common practice to conduct experiments on extra embryos, is this knowledge tantamount to a complicity on the part of the researcher who counts on the continuing assumption that as long as IVF technology stays status quo, there will be ample material with which to work? In other words, why, asks the critic, should we assume that extra embryos are necessarily "doomed embryos?" Viewed from the vantage point of a snapshot in time, it might seem that the decision to allocate embryos for research, having been made after a prior decision to discard or shelve them indefinitely, is indicative of a "nothing's lost" scenario, as these embryos would not have been put to better use anyway. However, the ongoing pattern of this practice makes the temporal assumptions at work in the "snapshot" scenario in this timeline less plausible. For as long as stem cell researchers are waiting to make use of extra embryos, IVF clinicians will lack an additional motivation to create embryos more responsibly and less wastefully. This response is similar to the one raised by those concerned about humane treatment of consumed animals: while the restaurant patron poised to order and eat veal did not cruelly slaughter the young cattle himself, were he and others not expected to eat veal with as much frequency, perhaps the practice of cruelly slaughtering baby cattle would itself occur less frequently, if not disappear altogether. Thus, according to this objection, a stem cell researcher is not merely a passive bystander vis-à-vis the fate of an embryo.

Whether this means that stem cell researchers intend, and do not merely foresee, the death of embryos, however, is another matter. It is well known that, almost by definition, a successful IVF program entails an expected surplus of embryos. Thus, if the argument for "intended" beyond "foreseen" is going to be made, it is going to have to be made against IVF first. At present, there seems to be no demonstrable evidence to suggest that the existence of stem cell researchers precipitates conditions of additional extra embryos, beyond the conditions that are already in keeping with normal IVF standards. In lieu of this evidence, the ethical burdens to adhere to the constraints imposed by double effect are met. At this point in our history, the demand for embryonic stem cells for research does not exceed the demand for those same cells for the purpose of IVF, and as such, there is no legitimate reason to hold stem cell research to a higher standard. Again, it bears pointing out, all of this assumes an agnosticism about the metaphysical and moral status of blastocysts. While this analysis grants that embryos are destroyed in stem cell research, it does not assume that embryos have the same status as human beings. If moral status is granted, then we must begin to doubt the accuracy of our calculations about the "overall good" according to the principle of double effect. However, to repeat, this status can only be granted from the perspective of particular theological worldviews. How are we to attend to the reality that in a pluralistic society, such as ours, competing worldviews, informed by competing faith commitments, vie to be influential in determining common public policy?

\section{Concluding Remarks on Public Policy in a Pluralist Society}

While new technologies for obtaining pluripotent stem cells continue to be developed and refined, we do not yet have an alternative to embryo-destroying techniques that produces functionally equivalent HSC lines. We have argued that, in a 
pluralist society, a permissive policy ought to be maintained regarding those practices, the objection to which involves a religious "leap of faith," at least when the potential benefits are so great for so many. We have additionally suggested that, at least regarding those excess embryos created for reproductive purposes, there are resources within objecting religious traditions to justify the research use of embryos that would be destroyed anyway. In light of these resources, we would like to suggest that the question of federal funding be raised anew in the narrow case of excess IVF embryos.

Determining the role of religion in the public square is its own industry, and we harbor no aspirations about forging a peace between individuals of faith opposed to the opportunities that technology have made available in the contemporary world and their opponents who vociferously object to any overriding deference to the religious perspective. As we have argued, the agnostic presumption favors engendering a policy of permissibility even more strongly in the case of stem cell research than in the case of other biomedical practices.

To say as much, however, is not ipso facto to yield to an idolatry of scientism, according to which we follow the mantra "if we can do it, we should do it." We should never afford the advancing frontiers of science a blank check, but rather keep a cautious eye in order to avoid an uncritical utilitarianism. Any proposed technology should not only positively impact the quality of lives of those suffering; it also must do so in an ethically responsible manner. Moreover, it behooves us to recognize that ours is not a strictly secular society, and so we should not dismiss out of hand doubts that emerge from within theological circles. Ultimately, in a pluralistic setting, religion should get a vote but not a veto, and certainly not a veto when so many lives hang in the balance. This said, to the extent that it is possible, we should always be looking for ways in research to be more humane and less wasteful, and more preserving, both in terms of our means and our ends, of a true "culture of life" on whose behalf all medical research is in the first place presumably conducted. Should a functionally equivalent alternative to embryo-destroying techniques be developed, then the question of permissibility ought to be raised again, just as we suggest the question of federal funding be raised again now.

While the value-neutral language of utilitarianism may have no hold over religious objectors to stem cell research, we have offered an argument from double effect that, though not as permissive as a purely secular position, works within the value-laden context of the religious objection. Following the continental philosopher Jürgen Habermas [32], we suggest that this sort of "translation" of secular ideas into a religious context is wholly appropriate in a pluralist society. At the same time, in some instances, we have noted that the critics of stem cell research have chosen to identify the linchpin of their religious identification with prohibitive aspects of their interpretation of scripture while ignoring, for example, a Gospel- endorsed "pro-life" culture which focuses on preventing starvation or affordable health care for the poor. We would ask that, rather than drawing battle lines in the culture wars that get played out every election cycle, partisans of both sides take one another's position seriously and work together to find any possible common ground between them. Should they find room for cooperation, even in the narrow domain of excess IVF embryos that will expire anyway, then a common policy on federal funding backed by the secularist and the citizen of faith alike might be agreed upon. Given the immense good that is at stake for individuals stricken with diseases that ignore religious affiliation, both sides in this debate would best be served and would best serve those in need by working within their different worldviews to find such a common ground where possible rather than exploiting these differences for political gain.

\section{Compliance with Ethics Guidelines}

Conflict of Interest Michael Roess and Andrew Flescher declare that they no conflict of interest.

Human and Animal Rights and Informed Consent This article does not contain any studies with human or animal subjects performed by any of the authors.

\section{References}

Papers of particular interest, published recently, have been highlighted as:

- Of importance

•- Of major importance

1. Kass L. Defending life and dignity. Wkly Stand. 2008;13(23). Retrieved from: http://www.weeklystandard.com/Content/Public/ Articles/000/000/014/752supcx.asp.

2.• Fort A, Yamada D, Hashimoto K, et al. Nuclear transcriptome profiling of induced pluripotent stem cells and embryonic stem cells identify non-coding loci resistant to reprogramming. Cell Cycle. 2015;14(8):1148-55. doi:10.4161/15384101.2014.988031. This article provides a thorough comparison of iPSs and hESCs using the best currently available techniques for inducing pluripotency. The authors find numerous differences that may have therapeutic implications for iPS based stem cell research and its therapeutic applications.

3. Magill G, Neaves W. Ontological and ethical implications of direct nuclear reprogramming. Kennedy Inst Ethics J. 2009;19(1):23-32.

4. Neri D. The race toward 'ethically universally acceptable' human pluripotent (embryonic-like) stem cells: only a problem of sources? Bioethics. 2011;25(5):260-6.

5. Brown M. No ethical bypass of moral status in stem cell research. Bioethics. 2013;27(1):12-9.

6. Daley GQ, Lensch MW, Jaenisch R, et al. Broader implications of defining standards for the pluripotency of iPSCs. Cell Stem Cell. 2009;4(3):200-1. doi:10.1016/j.stem.2009.02.009. author reply 202. 
7. Rosner M, Schipany K, Hengstschläger M. The decision on the "optimal" human pluripotent stem cell. Stem Cells Transl Med. 2014;3:553-9. This article provides a thorough comparison of available techniques for obtaining pluripotent stem cell lines along with a discussion of the differing capabilities of each and their suitability for research and therapeutic applications. Ethical issues with each are mentioned, though not discussed at length.

8. Hoffman D, Zellman G, Fair C, et al. Cryopreserved embryos in the United States and their availability for research. Fertil Steril. 2003;79(5):1063-9.

9. Hyun I. Bioethics and the future of stem cell research. New York, NY: Cambridge University Press; 2013. This book length review of stem cell ethics is laudable for its thoroughness, clarity, and the breadth of issues it discusses. It is perhaps the best primer for the newcomer to the field, though it was published before SCNT had been successfully used to create HSCs and is, for this reason, somewhat dated.

10. Kazutoshi T, Yamanaka S. Induction of pluripotent stem cells from mouse embryonic and adult fibroblast cultures by defined factors. Cell. 2006;126:663-76.

11. Ruetz T, Kaji K. Routes to induce pluripotent stem cells. Curr Opin Genet Dev. 2014;28:38-42. doi:10.1016/j.gde.2014.08.006. This review article provides a clear discussion of the current understanding of the process by which pluripotency is induced.

12. The President's Council on Bioethics. Alternative sources of human pluripotent stem cells [White paper]. 2005. Retrieved from https:// bioethicsarchive.georgetown.edu/pcbe/reports/white_paper/ fulldoc.html

13. Naam R. More than human. New York: Broadway Books; 2005.

14. Schwartz S, Regillo C, Lam B, et al. Human embryonic stem cellderived retinal pigment epithelium in patients with age-related macular degeneration and Stargardt's macular dystrophy: follow-up of two open-label phase 1/2 studies. Lancet. 2015;385(9967):509-16. This is a review of ongoing clinical trials involving hESC implantation to restore vision. It is the first to show medium to long-term safety and tolerability. Introduced cells were well tolerated for up to 37 months and among patients for a median of 22 months. It is worth noting that these trials are using hESCs while similar trials taking place at RIKEN in Japan are using iPSs.

15. Kass L. The wisdom of repugnance. New Repub. 1997;216(22): 17-26.
16. Park A. The stem cell hope: how stem cell medicine can change our lives. New York, NY: Plume; 2013.

17. Nadig R. Stem cell therapy - hype or hope? a review. J Conserv Dent. 2009;12(4):131-8. Retrieve from http:/www.ncbi.nlm.nih.gov/pmc/ articles/PMC2879724/.

18. Monroe K, Miller R, Tobis J. Introduction: framing the controversy. Fundamentals of the stem cell debate: the scientific, religious, ethical, and political issues. Berkeley: University of California Press; 2008. p. 1-9.

19. Solo P, Pressburg G. The promise and politics of stem cell research. Westport, CT: Praeger Press; 2007. p. 6.

20. Blendon RJ, Kim MK, Benson JM. The public, political parties, and stem-cell research. N Engl J Med. 2011;365:1853-6.

21. The Civil Society Institute. Voter's views on stem cell research [White paper]. 2004. Retrieved from http://www. civilsocietyinstitute.org/reports/stemcellresearchpaper.pdf.

22. Bryant P, Schwartz P. Stem cells. Fundamentals of the stem cell debate: the scientific, religious, ethical, and political issues. Berkeley: University of California Press; 2008. p. 37.

23. Thomson J. A defense of abortion. The problem of abortion. 2nd ed. Belmont, CA: Wadsworth Publishing; 1984. p. 173-87.

24. The President's Council on Bioethics. Human cloning and human dignity: an ethical inquiry [White paper]. 2002. Retrieved from https://bioethicsarchive.georgetown.edu/pcbe/reports/ cloningreport/

25. McCormick R. Who or what is a preembryo? Ky J Ethics. 1991;121(1):12.

26. Pence G. Medical ethics: accounts of the cases that shaped and defined medical ethics. 5th ed. New York: McGraw-Hill; 2008.

27. Miller R. Ethical issues in stem cell research, therapy, and public policy. Fundamentals of the stem cell debate: the scientific, religious, ethical, and political issues. Berkeley: University of California Press; 2008. p. 146-96.

28. Parfit D. Reasons and persons. Oxford: Oxford University Press; 1984. p. 245-80.

29. Hauser M. Moral minds. New York, NY: Harper Collins; 2006. p. 113-31. 221-223.

30. Pinker S. The moral instinct. NY times magazine. 2008. January 13 retrieved from http://www.nytimes.com/2008/01/13/magazine/ 13Psychology-t.html

31. Green R. Benefiting from evil: an incipient moral problem in human stem cell research. Bioethics. 2002;16(6):544-56.

32. Habermas J. Religion in the public square. Between naturalism and religion: philosophical essays. New York: Polity; 2008. 